\title{
Synthesis and Crystal Structure of Benzyl 4-(2-
} fluoro-4-(trifluoromethyl)phenyl)- 2,6,6-trimethyl1,4,5,6,7,8-hexahydroquinoline-3-carboxylate and Its DFT Analysis Combined with Bond Order Modeling in Terms of The Bond Critical Point Quantities

Zeki Büyükmumcu

Erciyes University: Erciyes Universitesi

Sema OZTURK YILDIRIM ( $\square$ ozturk@erciyes.edu.tr)

Erciyes Üniversitesi https://orcid.org/0000-0001-5962-5337

\section{Gökalp Çetin}

Hacettepe University: Hacettepe Universitesi

\section{Rahime Şimşek}

Hacettepe University: Hacettepe Universitesi

Ray J. Butcher

Howard University

\section{Research Article}

Keywords: 1,4-DHP, hexahydroquinoline, inflammation, X-ray structural analysis, spectra, QTAIM, Bond Order, Molecular Surface Analysis

Posted Date: November 17th, 2021

DOI: https://doi.org/10.21203/rs.3.rs-1068016/v1

License: (c) (i) This work is licensed under a Creative Commons Attribution 4.0 International License. Read Full License 


\section{Abstract}

Inflammation is the underlying cause of many diseases such as cardiovascular diseases, cancer and autoimmune diseases. Recently 1,4-dihydropyridine (1,4-DHP) compounds were found effective to reduce inflammation which contributes to development of inflammation associated diseases. Based on these data we synthesized to investigate this type of action of annulated 1,4-DHP molecule, benzyl 4-(2-fluoro4-(trifluoromethyl)phenyl)-2,6,6-trimethyl-5-oxo-1,4,5,6,7,8-hexahydroquinoline-3-carboxylate and proved the structure of this molecule by IR, ${ }^{1} \mathrm{H}-\mathrm{NMR},{ }^{13} \mathrm{C}-\mathrm{NMR}$, HMRS and X-ray crystallography.

X-ray analyses were conducted to find out the exact 3D structure of the mentioned molecule. The molecular structure crystallizes in triclinic space group, $\mathrm{P}-1$, with $a=7.0889(11) \AA, b=12.4861(18) \AA, c=$ 14.338(2) $\AA, a=66.899(4)^{\circ}, \beta=89.025(4)^{\circ}, \gamma=85.101(4)^{\circ}$ and $V=1162.9(3) \AA 3$. In the title molecule, $\mathrm{C}_{27} \mathrm{H}_{25} \mathrm{~F}_{4} \mathrm{NO}_{3}$, the cyclohexene ring is in a sofa conformation and the 1,4-dihydropyridine ring is in a slight boat conformation. In the 2-fluoro phenyl and benzyl rings form a dihedral angle of $13.6(1)^{\circ}$. In the crystal structure stabilized by the intra- and intermolecular $\mathrm{N}-\mathrm{H} \cdots \mathrm{O}, \mathrm{C}-\mathrm{H} \cdots \mathrm{O}$ and $\mathrm{C}-\mathrm{H} \cdots \mathrm{F}$ interactions. The molecules are linked together to form a dimer by $\mathrm{N}(1)-\mathrm{H}(1 \mathrm{~N}) \cdots \mathrm{O}(1)^{i}$ and $\mathrm{C}(2)-\mathrm{H}(2 \mathrm{~A}) \cdots \mathrm{O}(1)^{i}$ hydrogen bonds [symmetry code: (i) $x+1, y, z$ ], producing two $\mathrm{R}_{2}^{1}(6)$ rings.

Natural charge, QTAIM, bond order, molecular planarity and molecular surface analyses have been performed on the optimized geometry by DFT. Considering the quantities obtained at the bond critical poins, the chemical bonds are discussed for classification. The correlation between bond critical point quantities and the bond orders based on different definitions have been explored considering different bond order models from the literature. The Laplacian Bond Order (LBO) gives best correlation for four of five bond order models. All the bond order models with an exception of the model with parameter $G$ have approximately same correlation degree for $\mathrm{C}-\mathrm{C}$ bonds. For $\mathrm{C}-\mathrm{H}$ bonds, only bond model with parameters of electron density and the principle curvatures for LBO gives relatively good correlation with $R^{2}$ value of 0.943. The two phenyl rings of the structure have aromaticity comparable to benzene as deduced from QTAIM quantities and molecular planarity metrics. As a result of molecular surface analysis, the mass density, molecular polarity index, $v$ (the measure of charge balance), $\sigma_{\text {tot }}^{2} \cdot v$ (measure of intermolecular interactions) were calculated and compared with literature values.

\section{Introduction}

1,4-DHP scaffold which firstly discovered by Arthur Hantzsch has diverse biological activities depending on their effectiveness on different calcium channel types. Calcium channel modulators operate calcium entry through cells and by that cause cardiological benefits. As a result of this pharmacological action, they are widely used for the treatment and prevention of cardiovascular diseases [1, 2].

Chronic inflammation plays an important role of development of several inflammatory diseases. Inflammatory stimuli initiates signaling pathways those activate production of inflammatory mediators such as interleukin-1 $\beta$ (IL-1 $\beta$ ), interleukin-6 (IL-6), and tumor necrosis factor- $\alpha$ (TNF-a). Receptor activation 
by those mediators induce signaling pathways such as nuclear factor kappa-B (NF-kB), and Janus kinase (JAK)-signal transducer and activator of transcription (STAT). Dysfunction of NF-KB, MAPK, or JAK-STAT activity is related with inflammatory, autoimmune and metabolic diseases, and cancer. Thus inhibiting those pathways are an promising approach to prevent previously mentioned inflammatory associated diseases $[3,4]$.

1,4-DHP compounds have inflammation supressing activity via reactive oxygen species (ROS) or reducing of inflammation mediator secretion. Many 1,4-DHP derivatives have inflammation supressing properties in different cell cultures [5-11]. Depending on these findings we designed and synthesized an annulated 1,4-DHP compound, benzyl 4-(2-fluoro-4-(trifluoromethyl)phenyl)-2,6,6-trimethyl-5-oxo1,4,5,6,7,8-hexahydroquinoline-3-carboxylate, and elucidated structure of the compound by IR, ${ }^{1} \mathrm{H}-\mathrm{NMR}$,

${ }^{13} \mathrm{C}$-NMR, HRMS and X-ray crystallography. In vitro studies showed that the compound has supressing activity on immunomodulator pathways, IL-1 $\beta$, IL-6, TNF-a, NF-KB and TGF- $\beta$ (Unpublished data).

\section{Experimental}

\section{Instrumentation}

All chemicals used were purchased from Aldrich (USA) and were used without further purification. Purity of the synthesized compound was checked by thin layer chromatography (TLC) on Merck aluminum sheets (Germany), silica gel 60 F254, mobile phase ethyl acetate:n-hexane (1:1), and UV absorbing spots were detected under short-wavelength $(254 \mathrm{~nm})$ light (Camag UV Cabinet, Germany). Melting points were determined on a Thomas Hoover capillary melting point apparatus (USA) and uncorrected. Infrared spectra (IR) were recorded on Perkin Elmer Spectrum BX FT-IR (UK) equipped with MIRacle ATR accessory (PIKE Technologies, USA) and were reported in $\mathrm{cm}^{-1}$. ${ }^{1} \mathrm{H}-\mathrm{NMR}$ and ${ }^{13} \mathrm{C}-\mathrm{NMR}$ spectra were taken in dimethyl sulfoxide (DMSO- $\mathrm{d}_{6}$ ) solution on a Bruker Ultra Shield Spectrophotometer at $400 \mathrm{MHz}$ using tetramethylsilane (TMS) as internal standard. Chemical shifts were reported in parts per million (ppm). HRMS was realized by Agilent 6530 Accurate-Mass Q-TOF.

\section{General synthesis of benzyl 2,6,6-trimethyl-4-[2-fluoro-4- (trifluoromethyl)phenyl]-5-oxo-1,4,5,6,7,8- hexahydroquinoline-3-carboxylate}

The compound was synthesized via Hantzsch reaction. 4,4-dimethylcyclohexane-1,3-dione (1 mmol), 2fluoro-4-(trifluoromethyl)phenylbenzaldehyde $(1 \mathrm{mmol})$, benzyl acetoacetate $(1 \mathrm{mmol})$ and ammonium acetate $(5 \mathrm{mmol})$ were refluxed for eight hours in absolute methanol [12]. Reaction mixture was monitored by TLC and after completion of the reaction, it was cooled to room temperature. The obtained precipitate was filtered and crystallized from ethanol for further purification. The synthetic route was shown in Scheme 1. 


\section{Benzyl 4-(2-fluoro-4-(trifluoromethyl)phenyl)-2,6,6-trimethyl- 5-oxo-1,4,5,6,7,8-hexahydroquinoline-3-carboxylate}

Yellowish solid, m.p: 196-198, yield: 68\%. IR (v, cm-1) 3296 (N-H), 1698 (C=0, ester), 1649 (C=0, ketone). ${ }^{1} \mathrm{H}-\mathrm{NMR}\left(\delta, \mathrm{DMSO}-\mathrm{d}_{6}\right): 0.81\left(3 \mathrm{H} ; \mathrm{s} ; 6-\mathrm{CH}_{3}\right), 0.95\left(3 \mathrm{H} ; \mathrm{s} ; 6-\mathrm{CH}_{3}\right), 1.64-1.74\left(2 \mathrm{H} ; \mathrm{m}\right.$; quinoline $\left.\mathrm{H}^{7}\right), 2.27(3 \mathrm{H} ; \mathrm{s}$; 2- $\left.\mathrm{CH}_{3}\right), 2.48-2.50\left(2 \mathrm{H} ; \mathrm{m}\right.$; quinoline $\left.\mathrm{H}^{8}\right), 4.93-5.05\left(2 \mathrm{H}, \mathrm{q}, \mathrm{J}_{A B}=12.8 \mathrm{~Hz}, 32 \mathrm{~Hz}, \mathrm{COOCH}_{2} \mathrm{C}_{6} \mathrm{H}_{5}\right), 5.09(1 \mathrm{H}$; s; quinoline $\left.\mathrm{H}^{4}\right)$, 7.09-7.12 (2H, m; aromatic) 7.25-7.37 (4H, m, aromatic), $9.27(1 \mathrm{H}, \mathrm{s} ; \mathrm{NH}) .{ }^{13} \mathrm{C}-\mathrm{NMR}(\delta$, DMSO-d $\left.{ }_{6}\right): 18.4,22.9,24.1,24.7,31.8,33.9,39.4,64.7,101.1,108.0,112.1,112.4,120.8,122.1,124.8$, $127.7,127.8,128.0,128.2,131.8,131.9,136.6,139.4,139.5,146.7,150.1,157.6,160.1,166.2,199.2$. HRMS (ESI/Q-TOF) m/z: [M + H]+ Calcd for $\mathrm{C}_{27} \mathrm{H}_{25} \mathrm{~F}_{4} \mathrm{NO}_{3}$ 488.1804; Found 488.1860.

\section{X-Ray crystallography}

A single colourless chunk of the compound, $\mathrm{C}_{27} \mathrm{H}_{25} \mathrm{~F}_{4} \mathrm{NO}_{3}$, with the dimensions of $0.31 \times 0.25 \times 0.17 \mathrm{~mm}^{3}$ was used for data collection. X-Ray diffraction study was done on an Oxford Gemini-R single crystal diffractometer. The system was prepared with plane graphite monochromatized $\operatorname{MoK}_{a}(\lambda=0.71073 \AA)$ radiation at $100(2) \mathrm{K}$. The crystal orientation, cell refinement and intensity measurements were made using the program CrysalisPro. A multi scan absorption correction was applied to the X-ray data collection. A total of 26020 reflection (10761 unique) within the $\theta$ range of $\left(2.777<\theta<35.695^{\circ}\right)$ were collected in the $\omega$ scan mode. The integration method is used for absorption correction with $T_{\min }=0.966$ and $T_{\max }=0.981$. The structures were solved by direct method using the program SHELXT, and refined by full-matrix least-square techniques against $\mathrm{F}^{2}$ using SHELXL2016/6 [13]. The $\mathrm{N}$-bound $\mathrm{H}(1 \mathrm{~N})$ atom was located in a difference map and refined freely $[\mathrm{N}-\mathrm{H}=0.889(15) \AA]$. The remaining $\mathrm{H}$ atoms were positioned geometrically $\left[\mathrm{C}-\mathrm{H}=0.95,0.98\right.$ or $1.00 \AA ̊$ ] and refined using a riding model with $\mathrm{U}_{\text {iso }}(H)=1.2$ or $1.5 \mathrm{U}_{\mathrm{eq}}(\mathrm{C})$. A rotating group model was applied to the methyl group. The ORTEP-3 [14] for Windows program was used for generating the structure. The final refinement with 323 parameters converged at $R_{1}$ $=0.0426$ and Goodness of fit was 1.033. The largest and the lowest peak for electron density were 0.643 and $-0.581 \mathrm{e}^{-3}$, respectively.

\section{Computing details.}

The data collection for, $\left(\mathrm{C}_{27} \mathrm{H}_{25} \mathrm{~F}_{4} \mathrm{NO}_{3}\right)$, was performed with an Xcalibur, Ruby, Gemini (Diffractometer) $[15,16]$ at low temperature of 100(2) K. APEX2 and [15] SAINT software [16] was used for obtaining cell parameters [These are Bruker programs but the diffractometer is not. The correct programs should be CrysAlisPro: Reference: CrysAlisPRO CrysAlisPRO, Rigaku OD, Yarnton, England].

CrysAlis PRO 1.171.38.43 [17] Analytical numeric absorption correction using a multifaceted crystal model based on expressions derived by R.C. Clark \& J.S. Reid [18]. Empirical absorption correction using spherical harmonics, implemented in SCALE3 ABSPACK scaling algorithm. 
The geometry optimization of the molecule has been done the hybrid-GGA functional B3LYP [19] with standard basis set $6-31 \mathrm{G}(\mathrm{d}, \mathrm{p})$. The an initial geometry input for the optimization is taken from the analysis of $x$-ray structure data. There was no restriction applied during the optimization. The vibrational spectrum of the optimized geometry has been calculated to make certain of minimum in potential energy surface by checking absence of imaginary frequency. The optimization and the calculations of vibrational spectrum together with some other properties of the optimized molecule were carried out by Gaussian 09 program package [20]. The properties such as bond orders, molecular surface quantities, partial charges, the parameters of the topology analysis have been calculated by Multiwfn 3.8 [21] using the checkpoint file obtained from the geometry optimization.

\section{Results And Discussion}

In this study, benzyl 4-(2-fluoro-4-(trifluoromethyl)phenyl)-2,6,6-trimethyl-5-oxo-1,4,5,6,7,8hexahydroquinoline-3-carboxylate has been synthesized by Hantzsch reaction. According to this reaction mechanism aldehyde and $\beta$-ketoester formed an intermediate. This intermediate was converted to the target compound via ammonium acetate as nitrogen source. The structure of the compound was proved by using IR, ${ }^{1} \mathrm{H}-\mathrm{NMR},{ }^{13} \mathrm{C}$-NMR, HRMS and X-ray single-crystal diffraction. Detailed X-ray analyses were realized for further elucidation of the certain structure. The absorption bands of $3296 \mathrm{~cm}^{-1}, 1698 \mathrm{~cm}^{-1}$ and $1649 \mathrm{~cm}^{-1}$ verified nitrogen of the hexahydroquinoline ring, ester and ketone groups, respectively. In

${ }^{1} \mathrm{H}-\mathrm{NMR}$ spectra of the compound, singlet signals belonging to $-\mathrm{CH}_{3}$ group at 2nd position were seen at 2.27 ppm. Signals belonging to aromatic protons were seen at between 7.09-7.12 and 7.25-7.37 ppm. Singlet signal belonging to $\mathrm{N}-\mathrm{H}$ proton was seen at $9.27 \mathrm{ppm}$ which indicates closure of the hexahyroquinoline ring. The peaks belonging to other protons were determined in expected values of ${ }^{1} \mathrm{H}$ NMR spectra. The peaks in the ${ }^{13} \mathrm{C}$-NMR spectrum are consistent with the expected chemical shift values for the carbons in the molecule. In this context, $\mathrm{C}=0$ peaks in the ${ }^{13} \mathrm{C}$-NMR spectrum have expected values for an ester and a ketone, $166.2 \mathrm{ppm}, 199.2 \mathrm{ppm}$, respectively. The HRMS spectra of the compound were recorded using the electrospray ionisation-Q-TOF technique. Molecular ion peak $(\mathrm{M}+\mathrm{H})$ also base peak was seen in the spectra.

\section{X-Ray analysis of the title compound}

The three-dimensional structure of benzyl 4-(2-fluoro-4-(trifluoromethyl)phenyl)-1,4,5,6,7,8-hexahydro2,6,6-trimethyl-5-oxoquinoline-3-carboxylate was evaluated by $\mathrm{X}$-ray crystallography as shown in Figure 1. Selected bond lengths and angles are listed in Table 1. The molecular bond lengths and bond angles are in good agreement with related structures [22-25]. The (C1-C6) cyclohexene ring is in a sofa conformation with puckering parameters [26] of $\mathrm{Q}_{\mathrm{T}}=0.476$ (1) $\AA, \theta=63.4(1)^{\circ}$ and $\varphi=119.4(1)^{\circ}$. The 1,4-dihydropyridine ring (N1/C1/C6-C9) is in a slight boat conformation $\left[\mathrm{Q}_{\mathrm{T}}=0.249(1) \AA, \theta=105.2(1)^{\circ}\right.$ and $\varphi=353.9(1)^{\circ}$. In the 2-fluoro phenyl (F1/C21-C26) and benzyl (C15-C20) rings form a dihedral angle of $13.6(1)^{\circ}$. The molecules are linked together to form a dimer by $\mathrm{N}(1)-\mathrm{H}(1 \mathrm{~N}) \cdots \mathrm{O}(1)^{i}$ and $\mathrm{C}(2)-\mathrm{H}(2 \mathrm{~A})$ 
$\cdots 0(1)^{i}$ hydrogen bonds [symmetry code: (i) $x+1, y, z$ ] (Table 3 and Fig. 2), producing two $R$ (6) rings [27] into chains parallel to the $b$ axis. In the crystal structure stabilized by the intra- and intermolecular $\mathrm{N}-$ $\mathrm{H} \cdots \mathrm{O}, \mathrm{C}-\mathrm{H} \cdots \mathrm{O}$ and $\mathrm{C}-\mathrm{H} \cdots \mathrm{F}$ interactions. 
Table 1

Experimental information and refinement details obtained by XRD method for the compound $\mathrm{C}_{27} \mathrm{H}_{25} \mathrm{~F}_{4} \mathrm{NO}_{3}$.

\begin{tabular}{|c|c|}
\hline Formula & $\mathrm{C}_{27} \mathrm{H}_{25} \mathrm{~F}_{4} \mathrm{NO}_{3}$ \\
\hline Formula weight $\left(\mathrm{gmol}^{-1}\right)$ & 487.48 \\
\hline Crystal system & Triclinic \\
\hline Space group & $P-1$ \\
\hline a $(\AA)$ & $7.0889(11)$ \\
\hline $\mathrm{b}(\AA)$ & $12.4861(18)$ \\
\hline$c(\AA)$ & $14.338(2)$ \\
\hline $\mathrm{a}\left({ }^{\circ}\right)$ & $66.899(4)$ \\
\hline$\beta\left(^{\circ}\right)$ & $89.025(4)$ \\
\hline$g\left({ }^{\circ}\right)$ & $85.101(4)$ \\
\hline$V\left(\AA^{3}\right)$ & $1162.9(3)$ \\
\hline Z & 2 \\
\hline Radiation type & $\mathrm{MoK}_{\mathrm{a}}$ \\
\hline $\mathrm{D}_{\mathrm{x}}\left(\mathrm{Mg} \mathrm{m}^{-3}\right)$ & 1.392 \\
\hline$\mu\left(\mathrm{mm}^{-1}\right)$ & 0.112 \\
\hline $\mathrm{F}_{000}$ & 508 \\
\hline$T_{\max }, T_{\min }$ & $0.981,0.966$ \\
\hline Reflections read & 26020 \\
\hline Unique reflections & 10761 \\
\hline Reflections with $\mathrm{I}>2 \mathrm{~s}(\mathrm{I})$ & 10761 \\
\hline Refined parameters & 323 \\
\hline$q_{\max }, q_{\min }\left({ }^{\circ}\right)$ & $2.777,35.695$ \\
\hline \multirow[t]{3}{*}{ Index range } & $-11 \leq h \leq 11$ \\
\hline & $-20 \leq k \leq 20$ \\
\hline & $-23 \leq I \leq 23$ \\
\hline
\end{tabular}




\begin{tabular}{|ll|}
\hline Formula & $\mathrm{C}_{27} \mathrm{H}_{25} \mathrm{~F}_{4} \mathrm{NO}_{3}$ \\
\hline $\mathrm{R}\left[\mathrm{F}^{2}>2 \mathrm{~s}\left(\mathrm{~F}^{2}\right)\right]$ & 0.0426 \\
$\mathrm{WR}\left(\mathrm{F}^{2}\right)$ & 0.1170 \\
GOOF & 1.033 \\
\hline
\end{tabular}

Table 3

Hydrogen-bond geometry $\left(\AA,^{\circ}\right)$ for title compound, $\mathrm{C}_{27} \mathrm{H}_{25} \mathrm{~F}_{4} \mathrm{NO}_{3}$.

\begin{tabular}{|lllll|}
\hline $\boldsymbol{D}-\mathrm{H} \cdots \boldsymbol{A}$ & $\boldsymbol{D}-\mathrm{H}$ & $\boldsymbol{H} \cdots \boldsymbol{A}$ & $\boldsymbol{D} \cdots \boldsymbol{A}$ & $\boldsymbol{D}-\mathrm{H} \cdots \boldsymbol{A}$ \\
\hline $\mathrm{N}(1)-\mathrm{H}(1 \mathrm{~N}) \cdots \mathrm{O}(1)^{i}$ & $0.889(15)$ & $2.037(15)$ & $2.9047(9)$ & $164.9(14)$ \\
$\mathrm{C}(2)-\mathrm{H}(2 \mathrm{~A}) \cdots \mathrm{O}(1)^{i}$ & 0.99 & 2.55 & $3.3014(10)$ & 133.1 \\
\hline $\mathrm{C}(2)-\mathrm{H}(2 \mathrm{~B}) \cdots \mathrm{O}(2)^{i i}$ & 0.99 & 2.64 & $3.3869(12)$ & 132.5 \\
$\mathrm{C}(12)-\mathrm{H}(12 \mathrm{~A}) \cdots \mathrm{O}(2)$ & 0.98 & 2.30 & $2.8812(11)$ & 116.8 \\
$\mathrm{C}(12)-\mathrm{H}(12 \mathrm{C}) \cdots \mathrm{F}(1)^{i}$ & 0.98 & 2.59 & $3.1914(11)$ & 119.8 \\
\hline
\end{tabular}

\section{Theoretical analysis}

The optimized structure of the molecule is given in Figure 3. Some of the selected experimentally determined geometrical parameters are also given along with the calculated ones in Table 2. As seen from the figures (Fig. 1 and 3) and the table, there is an general agreement between the calculated and experimentaly obtained geometrical parameters. There are some deviations on the dihedral angle values possibly due to geometry optimization in gaseous phase different from the experiment. In the discusion of theoretical analysis, the labels given in Fig. 3 are preferred to be used. Frontier orbitals are used to make predictions about the molecular properties. The HOMO and LUMO energy levels are calculated to be -5.817 and $-1.635 \mathrm{eV}$, respectively. That is why the energy gap is equal to $4.183 \mathrm{eV}$, which can be used to compare its kinetic stability with similar molecules as done for other molecules [28]. HOMO and LUMO orbitals are shown in Figure 4. As seen from the figure, they are mostly located on and around the pyridine ring. The neighbouring phenyl ring connected to pyridine has a higher contribution in the case of LUMO. As seen from the figure, part of the orbitals located on the pyridine ring exhibits pi character. 
Table 2

Experimental and theoretical parameters of the $\mathrm{C}_{27} \mathrm{H}_{25} \mathrm{~F}_{4} \mathrm{NO}_{3}$ single crystal.

\begin{tabular}{|c|c|c|}
\hline Bond lengths [Å] & Experimental (XRD) & Calculated (B3LYP) \\
\hline \multicolumn{3}{|l|}{ Parameter } \\
\hline$F(1)-C(26)$ & $1.3499(10)$ & 1.343 \\
\hline$F(2)-C(27)$ & $1.3252(13)$ & 1.352 \\
\hline$F(3)-C(27)$ & $1.3436(15)$ & 1.350 \\
\hline$F(4)-C(27)$ & $1.3370(12)$ & 1.361 \\
\hline$O(1)-C(5)$ & $1.2357(9)$ & 1.228 \\
\hline$O(2)-C(13)$ & $1.2162(9)$ & 1.222 \\
\hline$O(3)-C(13)$ & $1.3578(9)$ & 1.361 \\
\hline$O(3)-C(14)$ & $1.4506(10)$ & 1.446 \\
\hline$N(1)-C(1)$ & $1.3703(9)$ & 1.381 \\
\hline$N(1)-C(9)$ & $1.3848(9)$ & 1.389 \\
\hline$C(4)-C(5)$ & $1.5357(10)$ & 1.545 \\
\hline$C(5)-C(6)$ & $1.4526(10)$ & 1.471 \\
\hline$C(7)-C(21)$ & $1.5259(10)$ & 1.533 \\
\hline$C(8)-C(13)$ & $1.4709(10)$ & 1.474 \\
\hline$C(9)-C(12)$ & $1.5031(10)$ & 1.507 \\
\hline Bond angles $\left[{ }^{\circ}\right]$ & Experimental (XRD) & Calculated (B3LYP) \\
\hline \multicolumn{3}{|l|}{ Parameter } \\
\hline$C(13)-O(3)-C(14)$ & $117.24(6)$ & 117.3 \\
\hline$C(1)-N(1)-C(9)$ & $122.58(6)$ & 123.2 \\
\hline$C(6)-C(1)-N(1)$ & $120.22(6)$ & 120.2 \\
\hline$C(6)-C(1)-C(2)$ & $123.43(6)$ & 123.61290 \\
\hline$N(1)-C(1)-C(2)$ & $116.25(6)$ & 116.2 \\
\hline$C(2)-C(3)-C(4)$ & $112.85(6)$ & 113.2 \\
\hline$C(3)-C(4)-C(5)$ & $110.53(6)$ & 110.2 \\
\hline$C(8)-C(7)-C(21)$ & $110.76(6)$ & 111.6 \\
\hline
\end{tabular}




\begin{tabular}{|lll|}
\hline Bond lengths $[\AA]$ & Experimental (XRD) & Calculated (B3LYP) \\
\hline$C(6)-C(7)-C(21)$ & $110.67(6)$ & 110.7 \\
\hline$F(1)-C(26)-C(25)$ & $116.99(7)$ & 117.7 \\
\hline$F(1)-C(26)-C(21)$ & $119.40(7)$ & 119.5 \\
\hline$F(2)-C(27)-F(4)$ & $106.84(10)$ & 106.4 \\
\hline$F(2)-C(27)-F(3)$ & $106.32(9)$ & 107.6 \\
\hline$F(4)-C(27)-F(3)$ & $106.04(9)$ & 106.6 \\
\hline$F(2)-C(27)-C(24)$ & $112.87(8)$ & 112.1 \\
\hline$F(4)-C(27)-C(24)$ & $111.79(8)$ & 111.5 \\
\hline$F(3)-C(27)-C(24)$ & $112.51(9)$ & 112.3 \\
\hline Torsion angles $\left.{ }^{\circ}\right]$ & Experimental (XRD) & Calculated (....) \\
\hline Parameter & & \\
\hline$C(9)-N(1)-C(1)-C(6)$ & $-11.67(11)$ & -10.7 \\
\hline$C(9)-N(1)-C(1)-C(2)$ & $164.84(7)$ & 169.46 \\
\hline$N(1)-C(1)-C(2)-C(3)$ & $163.36(6)$ & -155.4 \\
\hline$C(3)-C(4)-C(5)-O(1)$ & $-164.22(7)$ & 154.3 \\
\hline$C(11)-C(4)-C(5)-O(1)$ & $-43.94(10)$ & -84.7 \\
\hline$C(10)-C(4)-C(5)-O(1)$ & $74.36(9)$ & 33.4 \\
\hline
\end{tabular}

The dipole moment of the molecule is calculated to be 6.854 Debye, as expected qualitatively from its asymmetric structure. This asymmetric charge distribution results in bonding regions and atoms. The partial charges accumulated in atoms can be calculated by using different charge models. The natural charges obtained as a result of NBO analysis [29] are given in Table 4. Partial atomic charges strongly depend on electronegativity and its environment. There are five types of elements in the molecule; $\mathrm{C}, \mathrm{H}, \mathrm{F}$, $\mathrm{N}$, and $\mathrm{O}$ with electronegativity values of $2.55,2.2,4.00,3.04$ and 3.44 in Pauling scale, respectively. C, N, $\mathrm{O}$, and $\mathrm{F}$ are the second period element with the highest electronegativity values in agreement with periodic table trend. So, all the $\mathrm{H}$ atoms are expected to be positively charged with the value depending on bonding atom. They all are connected to $\mathrm{C}$ atoms with different environment. Their charge varies between 0.224 and 0.429 , corresponding to atoms 46 and 60 . All the hydrogens are bonded to $C$ atoms, there is only one $\mathrm{H}$ atom (with label 60 ) which is bonded to $\mathrm{N}$ atom. So the highest positive charge among the $\mathrm{H}$ atoms is expected for this one. However $\mathrm{C}$ atoms have partial charges with both negative and positive values ranging between -0.719 (C20) and 1.129 (C35). C20 is the methyl $C$ which is bonded to $C$ atom so it has strongly electropositive environment. On the other hand, C35 has a strong electroneative 
environment since it is $\mathrm{C}$ atom of $-\mathrm{CF}_{3}$ group. There is one nitrogen bonded to two $\mathrm{C}$ atoms and having partial charge of -0.587 as expected. 0 atoms have very narrow partial charge range between -0.554 and -0.630 , they are all connected to $\mathrm{C}$ atoms. There are four $\mathrm{F}$ atoms and florine is most electronegative known. However, the charges of florine atoms are between -0.318 and -0.368 , which are less negative than some of the $\mathrm{C}$ atoms, all the $\mathrm{O}$ atoms and the $\mathrm{N}$ atom. Each $\mathrm{F}$ atom in $-\mathrm{CF}_{3}$ has approximately the same partial charge value. However the $\mathrm{F}$ atom which is bonded to phenyl ring has relatively small negative charge value.

Table 4

Partial atomic calculated by NBO analysis.

\begin{tabular}{|llllllllllll|}
\hline No & Atom & $\mathrm{q}(\mathrm{NBO})$ & No & Atom & $\mathrm{q}(\mathrm{NBO})$ & No & Atom & $\mathrm{q}(\mathrm{NBO})$ & No & Atom & $\mathrm{q}(\mathrm{NBO})$ \\
\hline 1 & $\mathrm{~F}$ & -0.318 & 16 & $\mathrm{C}$ & -0.195 & 31 & $\mathrm{C}$ & -0.232 & 46 & $\mathrm{H}$ & 0.224 \\
\hline 2 & $\mathrm{~F}$ & -0.364 & 17 & $\mathrm{C}$ & 0.261 & 32 & $\mathrm{C}$ & -0.168 & 47 & $\mathrm{H}$ & 0.277 \\
\hline 3 & $\mathrm{~F}$ & -0.362 & 18 & $\mathrm{C}$ & -0.681 & 33 & $\mathrm{C}$ & -0.273 & 48 & $\mathrm{H}$ & 0.282 \\
\hline 4 & $\mathrm{~F}$ & -0.368 & 19 & $\mathrm{C}$ & -0.682 & 34 & $\mathrm{C}$ & 0.458 & 49 & $\mathrm{H}$ & 0.254 \\
\hline 5 & $\mathrm{O}$ & -0.567 & 20 & $\mathrm{C}$ & -0.719 & 35 & $\mathrm{C}$ & 1.129 & 50 & $\mathrm{H}$ & 0.229 \\
\hline 6 & $\mathrm{O}$ & -0.630 & 21 & $\mathrm{C}$ & 0.807 & 36 & $\mathrm{H}$ & 0.233 & 51 & $\mathrm{H}$ & 0.236 \\
\hline 7 & $\mathrm{O}$ & -0.554 & 22 & $\mathrm{C}$ & -0.125 & 37 & $\mathrm{H}$ & 0.253 & 52 & $\mathrm{H}$ & 0.244 \\
\hline 8 & $\mathrm{~N}$ & -0.587 & 23 & $\mathrm{C}$ & -0.069 & 38 & $\mathrm{H}$ & 0.236 & 53 & $\mathrm{H}$ & 0.246 \\
\hline 9 & $\mathrm{C}$ & 0.246 & 24 & $\mathrm{C}$ & -0.225 & 39 & $\mathrm{H}$ & 0.259 & 54 & $\mathrm{H}$ & 0.240 \\
\hline 10 & $\mathrm{C}$ & -0.493 & 25 & $\mathrm{C}$ & -0.233 & 40 & $\mathrm{H}$ & 0.237 & 55 & $\mathrm{H}$ & 0.240 \\
\hline 11 & $\mathrm{C}$ & -0.456 & 26 & $\mathrm{C}$ & -0.239 & 41 & $\mathrm{H}$ & 0.231 & 56 & $\mathrm{H}$ & 0.253 \\
\hline 12 & $\mathrm{C}$ & -0.128 & 27 & $\mathrm{C}$ & -0.233 & 42 & $\mathrm{H}$ & 0.248 & 57 & $\mathrm{H}$ & 0.243 \\
\hline 13 & $\mathrm{C}$ & 0.557 & 28 & $\mathrm{C}$ & -0.230 & 43 & $\mathrm{H}$ & 0.245 & 58 & $\mathrm{H}$ & 0.269 \\
\hline 14 & $\mathrm{C}$ & -0.163 & 29 & $\mathrm{C}$ & -0.066 & 44 & $\mathrm{H}$ & 0.259 & 59 & $\mathrm{H}$ & 0.301 \\
\hline 15 & $\mathrm{C}$ & -0.294 & 30 & $\mathrm{C}$ & -0.218 & 45 & $\mathrm{H}$ & 0.248 & 60 & $\mathrm{H}$ & 0.429 \\
\hline
\end{tabular}

Topological analysis of title molecule has been performed by means of QTAIM (quantum theory of atoms in molecules) [30]. QTAIM is one of the most powerfull tools to analyze chemical bonding [31]. Total 137 critical points have been obtained: There are 60 nuclear critical points associated with 60 nuclei, 68 bond critical points (63 of them is associated with chemical bonding and 5 of them correspond to nonbonding interactions) and finally 9 critical points associated with the rings formed with chemical bonding and nonbonding interactions. So, Poincare-Hopf relationship has been verified with the following equation:

$\mathrm{n}_{\mathrm{NCP}}-\mathrm{n}_{\mathrm{BCP}}+\mathrm{n}_{\mathrm{RCP}}-\mathrm{n}_{\mathrm{CCP}}=60-68+9-0=1$ 
For that reason it may be assumed that all the critical points are found considering this verification [21b].

According to QTAIM, atomic nuclei behave as an attractor which electron density gets a maximum [32]. The electron density values corresponding to nuclear critical points were obtained within the range between 0.422 a.u. ( $\mathrm{H}$ atom) and 419 a.u. ( $\mathrm{F}$ atom). The electron density at nuclei of free atoms is approximately found to be proportional to $Z^{3}$ by Hartree-Fock approximation results [30]. This relationship is also seen approximately from these values. However, electron density value changes depending on molecular environment.

As stated before, 68 bond critical points have been obtained and they are given with some quantities calculated in Table 5.1. Nonbonding interactions can be deduced from the $r$ values. Two of them may be interpretted as hydrogen bonding: 49(H) - 6(O) and 53(H) - 4(F) with distances $2.213 \AA$ and $2.644 \AA$, respectively. Their $\mathrm{H}$-bond binding energy can be calculated with electron density of the critical point using the equation, $\mathrm{BE} \approx-223.08 \times \rho\left(r_{\mathrm{BCP}}\right)+0.7423$ [33]. Since their $\rho\left(r_{\mathrm{BCP}}\right)$ values are 0.021 and 0.005 a.u., the binding energy values of these $\mathrm{H}$-bonds were calculated to be -3.942 and $-0.373 \mathrm{kcal} / \mathrm{mol}$, respectively. According to the classification given by the same publication, the first one may be classifed as a weak to medium strength hydrogen bond which electrostatic interaction is the major contribution to $\mathrm{H}$-bond. However, the second one is weak in strength which dispersion and electrostatic interactions are the sources of $\mathrm{H}$-bond. $\mathrm{X}-\mathrm{H}$...Y angles for them are $104.3^{\circ}$ and $147.4^{\circ}$, respectively. Although the second one is closer to $180^{\circ}$, its distance is longer than that of the first one. Therefore, the first one is very high in strength with respect to second one. 
Table 5.1

Bond critical points and some related quantities (a.u.) at the critical points.

\begin{tabular}{|lllllllll|}
\hline Atom Pair & $r(\AA)$ & $\rho(r)$ & $G(r)$ & $-G(r) / V(r)$ & $H(r) / \rho(r)$ & $\nabla^{2} \rho(r)$ & $E L F$ \\
\hline $50(\mathrm{H})$ & $22(\mathrm{C})$ & 1.095 & 0.286 & 0.039 & 0.117 & -1.037 & -1.028 & 0.988 \\
\hline $51(\mathrm{H})$ & $28(\mathrm{C})$ & 1.087 & 0.283 & 0.043 & 0.127 & -1.040 & -1.005 & 0.985 \\
\hline $49(\mathrm{H})$ & $22(\mathrm{C})$ & 1.093 & 0.289 & 0.037 & 0.109 & -1.057 & -1.074 & 0.990 \\
\hline $47(\mathrm{H})$ & $20(\mathrm{C})$ & 1.093 & 0.278 & 0.043 & 0.130 & -1.029 & -0.973 & 0.984 \\
\hline $55(\mathrm{H})$ & $27(\mathrm{C})$ & 1.086 & 0.284 & 0.042 & 0.125 & -1.043 & -1.016 & 0.986 \\
\hline $20(\mathrm{C})$ & $48(\mathrm{H})$ & 1.090 & 0.281 & 0.042 & 0.125 & -1.039 & -1.003 & 0.986 \\
\hline $20(\mathrm{C})$ & $46(\mathrm{H})$ & 1.095 & 0.276 & 0.047 & 0.144 & -1.017 & -0.933 & 0.981 \\
\hline $24(\mathrm{C})$ & $52(\mathrm{H})$ & 1.086 & 0.285 & 0.042 & 0.123 & -1.046 & -1.027 & 0.986 \\
\hline $26(\mathrm{C})$ & $54(\mathrm{H})$ & 1.086 & 0.284 & 0.042 & 0.125 & -1.043 & -1.017 & 0.986 \\
\hline $59(\mathrm{H})$ & $15(\mathrm{C})$ & 1.092 & 0.288 & 0.041 & 0.120 & -1.046 & -1.041 & 0.987 \\
\hline $25(\mathrm{C})$ & $53(\mathrm{H})$ & 1.086 & 0.286 & 0.041 & 0.121 & -1.047 & -1.033 & 0.987 \\
\hline $43(\mathrm{H})$ & $11(\mathrm{C})$ & 1.097 & 0.278 & 0.046 & 0.139 & -1.018 & -0.950 & 0.982 \\
\hline $45(\mathrm{H})$ & $10(\mathrm{C})$ & 1.098 & 0.276 & 0.046 & 0.142 & -1.013 & -0.932 & 0.981 \\
\hline $40(\mathrm{H})$ & $18(\mathrm{C})$ & 1.095 & 0.276 & 0.046 & 0.141 & -1.018 & -0.942 & 0.982 \\
\hline $57(\mathrm{H})$ & $30(\mathrm{C})$ & 1.086 & 0.285 & 0.042 & 0.124 & -1.044 & -1.021 & 0.986 \\
\hline $11(\mathrm{C})$ & $42(\mathrm{H})$ & 1.096 & 0.278 & 0.045 & 0.138 & -1.018 & -0.950 & 0.982 \\
\hline $10(\mathrm{C})$ & $44(\mathrm{H})$ & 1.099 & 0.275 & 0.045 & 0.140 & -1.013 & -0.933 & 0.982 \\
\hline $33(\mathrm{C})$ & $58(\mathrm{H})$ & 1.083 & 0.287 & 0.040 & 0.116 & -1.055 & -1.050 & 0.988 \\
\hline $18(\mathrm{C})$ & $39(\mathrm{H})$ & 1.091 & 0.281 & 0.044 & 0.131 & -1.033 & -0.986 & 0.984 \\
\hline $18(\mathrm{C})$ & $41(\mathrm{H})$ & 1.096 & 0.275 & 0.047 & 0.143 & -1.017 & -0.933 & 0.981 \\
\hline $31(\mathrm{C})$ & $56(\mathrm{H})$ & 1.084 & 0.286 & 0.042 & 0.121 & -1.051 & -1.037 & 0.987 \\
\hline $19(\mathrm{C})$ & $36(\mathrm{H})$ & 1.095 & 0.277 & 0.047 & 0.142 & -1.019 & -0.941 & 0.981 \\
\hline $19(\mathrm{C})$ & $37(\mathrm{H})$ & 1.094 & 0.279 & 0.044 & 0.134 & -1.026 & -0.967 & 0.983 \\
\hline $19(\mathrm{C})$ & $38(\mathrm{H})$ & 1.096 & 0.276 & 0.046 & 0.141 & -1.016 & -0.936 & 0.981 \\
\hline $60(\mathrm{H})$ & $8(\mathrm{~N})$ & 1.009 & 0.348 & 0.054 & 0.095 & -1.488 & -1.850 & 0.988 \\
\hline & $6(\mathrm{O})$ & 2.213 & 0.021 & 0.019 & 1.147 & 0.118 & 0.087 & 0.053 \\
\hline
\end{tabular}




\begin{tabular}{|c|c|c|c|c|c|c|c|c|}
\hline \multicolumn{2}{|c|}{ Atom Pair } & $r(\AA))$ & $\rho(r)$ & $G(r)$ & $-G(r) / V(r)$ & $H(r) / \rho(r)$ & $\nabla^{2} \rho(r)$ & $E L F$ \\
\hline $53(\mathrm{H})$ & $4(F)$ & 2.644 & 0.005 & 0.004 & 1.371 & 0.236 & 0.022 & 0.009 \\
\hline $22(C)$ & $23(C)$ & 1.508 & 0.260 & 0.057 & 0.209 & -0.834 & -0.639 & 0.966 \\
\hline $28(C)$ & $23(C)$ & 1.399 & 0.311 & 0.100 & 0.244 & -0.994 & -0.836 & 0.944 \\
\hline $28(C)$ & $27(C)$ & 1.396 & 0.312 & 0.099 & 0.241 & -0.999 & -0.850 & 0.945 \\
\hline $21(C)$ & $16(C)$ & 1.474 & 0.276 & 0.071 & 0.223 & -0.895 & -0.706 & 0.958 \\
\hline $23(C)$ & $24(C)$ & 1.401 & 0.310 & 0.098 & 0.243 & -0.990 & -0.833 & 0.945 \\
\hline $27(C)$ & $26(C)$ & 1.395 & 0.313 & 0.100 & 0.241 & -1.002 & -0.854 & 0.945 \\
\hline $20(C)$ & $17(C)$ & 1.507 & 0.256 & 0.060 & 0.219 & -0.840 & -0.619 & 0.960 \\
\hline $16(C)$ & $17(C)$ & 1.364 & 0.329 & 0.127 & 0.263 & -1.081 & -0.915 & 0.927 \\
\hline $24(C)$ & $25(C)$ & 1.394 & 0.313 & 0.100 & 0.242 & -1.003 & -0.856 & 0.945 \\
\hline $16(C)$ & 15(C) & 1.531 & 0.243 & 0.057 & 0.229 & -0.793 & -0.542 & 0.957 \\
\hline $26(C)$ & $25(C)$ & 1.397 & 0.312 & 0.098 & 0.241 & -0.998 & -0.850 & 0.946 \\
\hline $15(C)$ & $14(C)$ & 1.525 & 0.246 & 0.058 & 0.228 & -0.802 & -0.556 & 0.958 \\
\hline $15(C)$ & $29(C)$ & 1.533 & 0.244 & 0.057 & 0.226 & -0.798 & -0.551 & 0.958 \\
\hline $14(C)$ & $9(C)$ & 1.358 & 0.333 & 0.130 & 0.262 & -1.099 & -0.945 & 0.926 \\
\hline $14(C)$ & 13(C) & 1.471 & 0.277 & 0.072 & 0.228 & -0.886 & -0.692 & 0.956 \\
\hline $9(\mathrm{C})$ & 10(C) & 1.505 & 0.259 & 0.062 & 0.220 & -0.844 & -0.628 & 0.960 \\
\hline $29(C)$ & $34(C)$ & 1.397 & 0.317 & 0.101 & 0.238 & -1.017 & -0.884 & 0.946 \\
\hline $10(C)$ & $11(\mathrm{C})$ & 1.532 & 0.244 & 0.056 & 0.223 & -0.801 & -0.559 & 0.960 \\
\hline $29(C)$ & $30(C)$ & 1.400 & 0.310 & 0.100 & 0.245 & -0.992 & -0.830 & 0.944 \\
\hline $34(C)$ & $33(C)$ & 1.388 & 0.321 & 0.103 & 0.238 & -1.033 & -0.913 & 0.946 \\
\hline $13(\mathrm{C})$ & $12(\mathrm{C})$ & 1.545 & 0.247 & 0.056 & 0.220 & -0.803 & -0.570 & 0.961 \\
\hline $11(\mathrm{C})$ & $12(\mathrm{C})$ & 1.542 & 0.243 & 0.056 & 0.225 & -0.790 & -0.544 & 0.959 \\
\hline $18(\mathrm{C})$ & $12(\mathrm{C})$ & 1.536 & 0.243 & 0.056 & 0.224 & -0.794 & -0.549 & 0.960 \\
\hline $30(C)$ & $31(\mathrm{C})$ & 1.393 & 0.313 & 0.101 & 0.243 & -1.002 & -0.851 & 0.944 \\
\hline $33(C)$ & $32(C)$ & 1.395 & 0.310 & 0.101 & 0.247 & -0.996 & -0.830 & 0.942 \\
\hline $12(\mathrm{C})$ & 19(C) & 1.548 & 0.237 & 0.055 & 0.229 & -0.780 & -0.519 & 0.957 \\
\hline $31(C)$ & $32(C)$ & 1.397 & 0.310 & 0.101 & 0.246 & -0.995 & -0.832 & 0.943 \\
\hline
\end{tabular}




\begin{tabular}{|lllllllll|}
\hline Atom Pair & $r(\AA)$ & $\rho(r)$ & $G(r)$ & $-G(r) / V(r)$ & $H(r) / \rho(r)$ & $\nabla^{2} \rho(r)$ & $E L F$ \\
\hline $32(\mathrm{C})$ & $35(\mathrm{C})$ & 1.502 & 0.274 & 0.061 & 0.201 & -0.891 & -0.732 & 0.967 \\
\hline $17(\mathrm{C})$ & $8(\mathrm{~N})$ & 1.389 & 0.301 & 0.249 & 0.351 & -1.530 & -0.844 & 0.708 \\
\hline $8(\mathrm{~N})$ & $9(\mathrm{C})$ & 1.381 & 0.306 & 0.261 & 0.355 & -1.547 & -0.850 & 0.701 \\
\hline $22(\mathrm{C})$ & $7(\mathrm{O})$ & 1.446 & 0.236 & 0.224 & 0.412 & -1.354 & -0.381 & 0.571 \\
\hline $6(\mathrm{O})$ & $21(\mathrm{C})$ & 1.222 & 0.405 & 0.706 & 0.504 & -1.712 & 0.049 & 0.449 \\
\hline $21(\mathrm{C})$ & $7(\mathrm{O})$ & 1.361 & 0.295 & 0.329 & 0.418 & -1.551 & -0.515 & 0.566 \\
\hline $5(\mathrm{O})$ & $13(\mathrm{C})$ & 1.228 & 0.396 & 0.710 & 0.516 & -1.682 & 0.176 & 0.427 \\
\hline $1(\mathrm{~F})$ & $34(\mathrm{C})$ & 1.343 & 0.259 & 0.401 & 0.524 & -1.406 & 0.145 & 0.363 \\
\hline $4(\mathrm{~F})$ & $35(\mathrm{C})$ & 1.361 & 0.268 & 0.307 & 0.439 & -1.466 & -0.340 & 0.519 \\
\hline $35(\mathrm{C})$ & $3(\mathrm{~F})$ & 1.350 & 0.273 & 0.334 & 0.451 & -1.484 & -0.288 & 0.495 \\
\hline $35(\mathrm{C})$ & $2(\mathrm{~F})$ & 1.352 & 0.272 & 0.330 & 0.450 & -1.481 & -0.291 & 0.497 \\
\hline
\end{tabular}

Electron density, $\rho\left(r_{\mathrm{BCP}}\right)$ values can be used to classify the chemical bonding. If $\rho\left(r_{\mathrm{BCP}}\right)$ is greater than 0.20 a.u. it is covalent (shared) bonding. The bonding type is ionic, hydrogen, van der Waals..., if its value is less than 0.10 a.u. [32]. As given in Table 3, all the chemical bonds can be classifed as covalent due to their electron densities at the BCP. Its value vary between 0.236 a.u. ( C22-07) and 0.405 a.u. ( C21-06 ). 07 is bonded to two $\mathrm{C}$ atoms so that it is expected that it is approximately single bond since $\mathrm{C} 21-\mathrm{O} 6$ bond is expected to be double bond due to fact that it is only bonded to C21. Bader proposed bond order equation making a analogy with Pauling's relationship as follows:

$\mathrm{n}=\exp (a(\rho-b))$

where $\mathrm{a}$ and $\mathrm{b}$ are the coefficients which can be determined considering single, double, triple $\mathrm{C}-\mathrm{C}$ bond crtical point electron densities. By fitting this equation, they are determined to be 6.862 and 0.243 , respectively [30-34].The value of $b$ is approximately equal to the single $\mathrm{C}-\mathrm{C}$ bond critical point electron density. The findings of this study for two $\mathrm{C}-\mathrm{O}$ bonds given above are consistent with this eqaution. The lowest electron density value ( 0.237 a.u.) is obtained for $\mathrm{C} 12-\mathrm{C} 19$ which is clearly single bond because three hydrogen atoms bonded to $\mathrm{C} 19$. $\mathrm{C} 9-\mathrm{C} 14$ has the highest electron density value (0.333 a.u.), which seems to have the highest bond order. This is also reasonable considering the atoms bonded to atoms of this pair. The bond order of C-C bonds for the phenyl ring C29-C30-C31-C32-C33-C34 should be around 1.5. Their electron densities have a quite narrow range between $0.310-0.321$ a.u.. This shows its aromaticity comparable to benzene.

The negative ratio of the kinetic to potential energy densities, $-G(r) / V(r)$ can also be used to examine bonding character $[35,36]$. If this ratio is less than 0.5 , then it is expected to covalent bonding. The value 
between 0.5 and 1.0 indicates partially ionic bond [35]. The values between 0.095 and 0.524 have been obtained for the bonds of the title molecule. $\mathrm{C}-\mathrm{O}$ and $\mathrm{C}-\mathrm{F}$ bonds have the values around 0.5 which is the border between covalent and partially ionic bond. This may be attributed to electronegativity differences between bonding atoms. $\mathrm{H}(\mathrm{r}) / \rho(r)$ is defined as Bond degree (BD) by Espinosa et al [37]. The more negative $\mathrm{BD}$ value indicates the stronger bond. In the table, the lowest $\mathrm{BD}$ value belongs to $\mathrm{C} 21-06$ bond which has the highest electron density as well. Its value is -1.712 a.u. Both the electron density and bond degree indicate that this bond is the strongest bond. Depending on the sign of the Laplacian, $\nabla^{2} \rho(r)$, the type of bonding may be estimated also. The negative and positive value indicates covalent and ionic bonding, respectively. Sometimes, the low positive value of the Laplacian may be obtained for a polar covalent bond such as $\mathrm{CO}[21 \mathrm{~b}]$. Most of the Laplacians for the molecule is negative. Two C-O and one C$\mathrm{F}$ bond have very small positive values as stated for $\mathrm{CO}$.

The Electron Localization Function (ELF) [38] has a value between 0.0 and 1.0. The larger ELF value indicates more localized electrons which is a sign of a covalent bond, lone pair etc. As seen from Table 5.1 all the $\mathrm{C}-\mathrm{H}$ and $\mathrm{C}-\mathrm{C}$ bonds have ELF values very close to 1.0. However relatively polar bonds have smaller ELF values. The F1-C34 bond which has a high electronegativity difference between bonding atoms has the lowest ELF value, 0.363 .

The relationships between covalent bond order defined by Cioslowski et al. [39] and the parameters derived from a topological analysis of the electron density have been explored by Howard and Lamarche [34]. They have studied the bonds between $C$ and five different elements (C, N, O, S, and P). The bond order values have been fitted to equations including the electron density $(\rho)$, the square of the electron density $\left(\rho^{2}\right)$, the Laplacian of the electron density $\left(\nabla^{2} \rho\right)$, the principle curvatures $\left(\lambda_{12}\left(=\lambda_{1}+\lambda_{2}\right)\right.$ and $\left.\lambda_{3}\right)$, the kinetic energy density $(G)$. As a result, the multiple linear description with $\rho, \lambda_{12}$ and $\lambda_{3}$ was concluded to recommend, since it worked well for all the bonds considered. In this study, the four bond models and Bader bond model considered in the study of Howard and Lamarche [34] have been used to study C-C and $\mathrm{C}-\mathrm{H}$ bonds in the title molecule. Other bonds were not studied due to lack of sufficient data for fitting in the title molecule. Different from their study considering bond order definition by Ciolowski et al., the four different bond order definitions (MBO (Mayer Bond Order) [40], FBO (Fuzzy Bond Order) [41], LBO (Laplacian Bond Order) [42], IBSI (Intrinsic Bond Strength Index) [43]) have been considered to fit the equations of four different bond order models. The fitting was done using regression LibreOffice 7.1 Calc [44]. The coefficients obtained by fitting are tabulated in Table 5.2. Among the bond order definitions, LBO gives the best R-squared values (greater than 0.990) for the bond order models 1-3 and Bader bond order model. Only the bond order model 4 which is defined by only the kinetic energy density $(G)$ get the highest $\mathrm{R}$-squared value for bond order definition other than LBO. Average $\mathrm{R}^{2}$ values for each bond order model is also given in the same table and they are approximately the same for the first three models. The weakest correlation in average was obtained for Bader model. Although this model gives the weakest correlation in average, its $\mathrm{R}^{2}$ value is good enough for LBO. In general, R-squared values of the LBO obtained in this study are better than that of the values obtained by Howard and Lamarche [34]. The best value among the all models and bond order definitions was obtained for model 2 for LBO, although its $\mathrm{R}^{2}$ value is little 
bit larger than Model 1 and 3 with a negligible extent. Model 2 is the recommended in the study by Howard and Lamarche [34]. They recommended this model due to their well working for all the cations, anions, neutral and charged radicals. Its elagent and simple physical interpretation play also important role for its recommendation, since $\rho$ and $\lambda_{3}$ are the measure for the $\sigma$ character and the curvatures perpendicular to the bond $\left(\lambda_{1}\right.$ and $\left.\lambda_{2}\right)$ measure the degree of $\pi$ character. As a result, it can be said that LBO has better correlations with the electron density $(\rho)$, the square of the electron density $\left(\rho^{2}\right)$, the Laplacian of the electron density $\left(\nabla^{2} \rho\right)$, the principle curvatures $\left(\lambda_{12}\left(=\lambda_{1}+\lambda_{2}\right)\right.$ and $\left.\lambda_{3}\right)$ with respect to other models. The model 4 which is exceptionally not best for LBO includes only the kinetic energy density $(G)$ as a parameter and the best result is obtained for MBO with the $\mathrm{R}^{2}$ value of 0.971 . 
Table 5.2

Bond order model coefficients for $\mathrm{C}-\mathrm{C}$ bonds.

\begin{tabular}{|c|c|c|c|c|c|c|c|c|c|}
\hline & Intercept & $c\left(\lambda_{12}\right)$ & $c\left(\lambda_{3}\right)$ & $c(\rho)$ & $c\left(\rho^{2}\right)$ & $c\left(\nabla^{2} \rho\right)$ & $c(G)$ & $\mathrm{R}^{2}$ & Std.Err. \\
\hline & Model 1 & & & & & & & & \\
\hline MBO & -2.612 & & & 22.750 & & 3.614 & & 0.956 & 0.053 \\
\hline FBO & -2.302 & & & 22.031 & & 3.730 & & 0.925 & 0.059 \\
\hline LBO & -1.003 & & & 7.545 & & -0.217 & & 0.994 & 0.023 \\
\hline IBSI & -1.107 & & & 9.867 & & 1.666 & & 0.958 & 0.020 \\
\hline \multirow[t]{2}{*}{ Average } & & & & & & & & 0.958 & \\
\hline & Model 2 & & & & & & & & \\
\hline MBO & 0.831 & 1.039 & -4.646 & 7.228 & & & & 0.978 & 0.039 \\
\hline FBO & 0.813 & 1.883 & -4.579 & 7.510 & & & & 0.942 & 0.053 \\
\hline LBO & -0.942 & 0.618 & -0.967 & 9.225 & & & & 0.995 & 0.020 \\
\hline IBSI & 0.146 & 0.180 & -1.105 & 2.557 & & & & 0.931 & 0.026 \\
\hline \multirow[t]{2}{*}{ Average } & & & & & & & & 0.962 & \\
\hline & Model 3 & & & & & & & & \\
\hline MBO & 2.411 & & & -13.970 & 58.291 & 2.735 & & 0.976 & 0.040 \\
\hline FBO & 0.868 & & & -1.141 & 36.785 & 3.176 & & 0.936 & 0.056 \\
\hline LBO & -0.067 & & & 0.708 & 10.853 & -0.381 & & 0.994 & 0.022 \\
\hline |BSI & -0.693 & & & 6.843 & 4.799 & 1.594 & & 0.959 & 0.020 \\
\hline \multirow[t]{2}{*}{ Average } & & & & & & & & 0.966 & \\
\hline & Model 4 & & & & & & & & \\
\hline MBO & 0.396 & & & & & & 9.984 & 0.971 & 0.042 \\
\hline FBO & 0.560 & & & & & & 8.235 & 0.916 & 0.061 \\
\hline LBO & 0.369 & & & & & & 11.390 & 0.944 & 0.068 \\
\hline IBSI & 0.178 & & & & & & 3.688 & 0.937 & 0.024 \\
\hline \multirow[t]{2}{*}{ Average } & & & & & & & & 0.942 & \\
\hline & $\begin{array}{l}\text { Bader } \\
\text { Model }\end{array}$ & & & & & & & & \\
\hline $\ln (\mathrm{MBO})$ & -1.495 & & & 5.870 & & & & 0.933 & 0.053 \\
\hline
\end{tabular}




\begin{tabular}{|c|c|c|c|c|c|c|c|c|}
\hline & Intercept & $c\left(\lambda_{12}\right)$ & $c\left(\lambda_{3}\right)$ & $c(\rho)$ & $c\left(\rho^{2}\right)$ & $c\left(\nabla^{2} \rho\right) \quad c(G)$ & $\mathrm{R}^{2}$ & Std.Err. \\
\hline $\ln (\mathrm{FBO})$ & -1.159 & & & 4.769 & & & 0.872 & 0.062 \\
\hline $\ln (\mathrm{LBO})$ & -1.676 & & & 6.739 & & & 0.991 & 0.021 \\
\hline $\ln (\mid \mathrm{BSSI})$ & -2.334 & & & 5.564 & & & 0.920 & 0.055 \\
\hline Average & & & & & & & 0.929 & \\
\hline
\end{tabular}

$\mathrm{C}-\mathrm{H}$ bond order coefficients are not tabulated due to its poor correlations for all the bond order models and the bond order definitions. There is only one exception which has greater than $\mathrm{R}^{2}$ value greater 0.900 : Bond model 2 for LBO gives $R^{2}$ value of 0.943 with the coefficients of $-0.852\left(\lambda_{12}\right),-1.251\left(\lambda_{3}\right)$, and 4.067 $(\rho)$.

As stated before, there are 9 critical points associated with the rings formed with chemical bonding and nonbonding interactions. There are four rings formed as a result of chemical bonding completely. The quantities that belong to these rings are tabulated in Table 5.3. The highest electron density belong to two phenyl rings (C23-C24-C25-C26-C27-C28 and C29-C30-C31-C32-C33-C34). $\rho\left(\Gamma_{\mathrm{BCP}}\right)$ and $\nabla^{2} \rho\left(\Gamma_{\mathrm{BCP}}\right)$ of the rings can be employed to make comparison aromaticity of rings quantitatively. The negative curvature of electron density perpendicular to ring plane at RCP gives us the measure of aromaticity [21b,45]. It was concluded that direct correlations of HOMA aromaticity index with the values of $\rho\left(\Gamma_{B C P}\right)$ and $\nabla^{2} \rho\left(\Gamma_{B C P}\right)$ can be established [45]. QTAIM analysis of benzene optimized at the same theory level with title molecule has been done to get reference values for comparison of aromaticity. $\rho\left(\Gamma_{B C P}\right)$ and $\nabla^{2} \rho\left(\Gamma_{B C P}\right)$ were calculated to be 0.020 and 0.163 a.u., respectively, for benzene. The curvature of electron density perpendicular to ring plane at its RCP was calculated to be -0.015 a.u. As the values for these quantities are the same with the values obtained for phenyl rings of the title molecule, these rings are conclude to have the same aromaticity leveel with the benzene. On the other hand, the other two rings have aromaticty lower than the phenyl rings, when the values are compared. In addition to QTAIM analysis, molecular planarity analysis based on two metrics proposed by Tian Lu [46] has been done for these rings. These two metrics, to characterize planarity of molecules quantitatively are molecular planarity parameter (MPP) and span of deviation from plane (SDP). These parameters are complementary to each other [46]. MPP and SDP values are given in the same table, both of them changes in parallel. As they get closer to zero, they tend to get more planarity. Two phenyl rings have the highest planarity. This is an expected result, since planarity is known to be important factor for aromaticity [47]. 
Table 5.3

Electron density (a.u) and curvature (a.u) at the ring critical points and planarity parameters of rings.

\begin{tabular}{|lllll|}
\hline Ring & $\boldsymbol{\rho}$ & Curvature & MPP & SDP \\
\hline C9-C10-C11-C12-C13-C14 & 0.017 & -0.010 & 0.177 & 0.530 \\
\hline N8-C9-C14-C15-C16-C17 & 0.019 & -0.013 & 0.075 & 0.188 \\
\hline C23-C24-C25-C26-C27-C28 & 0.020 & -0.015 & 0.004 & 0.010 \\
\hline C29-C30-C31-C32-C33-C34 & 0.020 & -0.015 & 0.002 & 0.006 \\
\hline
\end{tabular}

Molecular surface analysis has been done using the ESP evaluation code of Multiwfn 3.3 based on LIBRETA library [48]. The van der Waals ( $\mathrm{vdW}$ ) surface of the molecule was used for performin the ESP analysis with the default value of 0.001 a.u. isosurface of electron density [49]. A general interaction properties function (GIPF) proposed by Murray et al. can be used to determine several properties by the quantites obtained from molecular surface analysis. $\Pi$ (a measure of local polarity), $\sigma^{2}$ tot (a measure of the variability of the potential on the surface), $v$ (a measure of the balance between positive and negative regions) are used in their function [50]. The quantities obtained from this analysis are given Table 6. Density values can be calculated by using expression $M / V$, where $M$ is molecular mass and $V$ is the van der Waals volume [51]. The density value calculated in this way is $1.49 \mathrm{~g} / \mathrm{cm}^{3}$ which is very close to experimental value $1.392 \mathrm{~g} / \mathrm{cm}^{3}$ given in Table 1. This calculation has been improved making electrostatic interaction correction by Politzer et al. [52]:

Table 6

Quantities obtained from molecular surface analysis.

\begin{tabular}{|ll|}
\hline Volume & $\mathbf{5 4 3 . 1 \AA ^ { 3 }}$ \\
\hline Mass/Volume & $1.49 \mathrm{~g} / \mathrm{cm}^{3}$ \\
\hline Surface Area & $455.6 \AA^{2}$ \\
\hline$\sigma_{\text {tot }}^{2}$ & $173.7 \mathrm{kcal}^{2} / \mathrm{mol}^{2}$ \\
\hline$v$ & 0.250 \\
\hline$\sigma_{\text {tot }}^{2} v$ & $43.4 \mathrm{kcal} / \mathrm{mol}^{2}$ \\
$\Pi$ & $11.2 \mathrm{kcal} / \mathrm{mol}$ \\
\hline $\mathrm{MPI}$ & $11.2 \mathrm{kcal} / \mathrm{mol}$ \\
\hline
\end{tabular}

\section{$\rho=a\left(M / V_{m}\right)+\beta\left(\sigma^{2}{ }_{\text {tot }} v\right)+\square$}


where $a=0.9183, \beta=0.0028$ and $\Delta=0.0443$. In this equation, the second factor is the product of $\sigma_{\text {tot }}^{2}$ and $v$ is proposed to make correction for intermolecular interaction through surface electrostatic potentials in the solid phase. The values of $\sigma_{\text {tot }}^{2} v$ were obtained within a range of 0.5 and $62.5 \mathrm{kcal}^{2} / \mathrm{mol}^{2}$ for the molecules studied by Murray et al. [50]. The value for the title molecule is $43.4 \mathrm{kcal}^{2} / \mathrm{mol}^{2}$ which is higher than mean value considering this study. The parameters in the equation were obtained using the crystals containing $\mathrm{C}, \mathrm{H}, \mathrm{N}, \mathrm{O}[50]$. Although one of the elements of the title compound, $\mathrm{F}$ was not included and B3PW91 functional was used in this fit, it may be meaningful to calculate the density of the title compound by using this equation to make comment on the effect of intermolecular interaction. By this equation, the density was found to be $1.53 \mathrm{~g} / \mathrm{cm}^{3}$ which has more deviation than previous result from experimental value. Of course, the increase does not come from the intermolecular interactions, since the coefficient of $M / V$ is reduced to 0.9183 . However, the equation shows that the density increase with an increase of interaction which results in the reduction of intermolecular space. A larger deviation probably comes from the extra atom which was not included and the different functional was used in the fitting[52].

As stated before, $v$ is the measure of charge balance between positive and negative regions. Its value get maximum value of 0.250 as in our results, if $\sigma_{\text {tot }}^{2}$ for the positive and negative regions are equal. These values are aprroximately equal for the title molecule, so the molecular interaction with a similar extent through both its positive and negative regions may be concluded as stated in original study [50]. $\Pi$ gives us a measure of local polarity (or charge separation) for a molecule. So, very large values may be obtained even for a molecule having a zero-dipole moment. It has values between 0 and approximately $20 \mathrm{kcal} / \mathrm{mol}$ for the molecules studied in the original reference [50]. It is obtained to be $11.2 \mathrm{kcal} / \mathrm{mol}$ for our molecule as given before. This value indicates that the title molecule has moderate value of local polarity considering the molecules in the original reference. For a similar purpose to quantify molecular polarity due to uneven ESP distribution, another index, MPI (the molecular polarity index) is defined by Tian Lu and coworkers [53]. In their study, the calculated MPI values of the cyclo[18]carbon, ethane, ethene, and benzene are obtained to be $2.6,2.6,6.7$, and $8.4 \mathrm{kcal} / \mathrm{mol}$, respectively. The calculated value for MPI is $11.2 \mathrm{kcal} / \mathrm{mol}$ which is higher than benzene which has the highest value among the molecules given by Tian Lu and coworkers [53].

\section{Conclusion}

In this study, benzyl 4-(2-fluoro-4-(trifluoromethyl)phenyl)-2,6,6-trimethyl-5-oxo-1,4,5,6,7,8-

hexahydroquinoline-3-carboxylate has been synthesized by modified Hantzsch method and characterized by using IR, ${ }^{1} \mathrm{H}-\mathrm{NMR},{ }^{13} \mathrm{C}$-NMR, HRMS methods and X-ray single-crystal diffraction.

Natural charge, QTAIM, bond order, molecular planarity and molecular surface analyses have been performed on the geometry of title molecule optimized which has general agreement with experimental data. Two hydrogen bonds were identified and classifed as the weak and the weak to medium strength as a result of electron density at the BCP. The chemical bonds are classified based on the quantities 
obtained for BCPs. The correlation between BCP quantities and the bond orders based on different definitions have been explored considering different bond order models from the literature. LBO gives the best correlation for four of five bond order models. Considering slightly higher $\mathrm{R}^{2}$ value and its practical usage, it can be said that the best bond order model includes the parameters $\rho$ and $\lambda_{3}$ which are the measure for the $\sigma$ character and the parameter $\lambda_{12}$ measuring the degree of $\pi$ character for $\mathrm{C}-\mathrm{C}$ bonds. However all the bond order models with an exception of the model with parameter $G$ have approximately same correlation degree. For $\mathrm{C}-\mathrm{H}$ bonds, only bond model 2 for $\mathrm{LBO}$ gives relatively good correlation with $R^{2}$ value of 0.943 . All the others have $R^{2}$ value lower than 0.900 . Two phenyl rings of the structure have aromaticity comparable to benzene as deduced from QTAIM quantities and molecular planarity metrics.

The mass density, molecular polarity index, $v$ (the measure of charge balance), $\sigma_{\text {tot }}^{2} . v$ (measure of intermolecular interactions) were calculated based on molecular surface analysis. The molecular polarity index obtained is higher than benzen. The $\sigma_{\text {tot }}^{2} . v$ value of the molecule was found to be higher than average value of the reference work [50]. The charge balance may be said to be nearly satisfied considering $v$ value.

\section{Declarations}

Acknowledgements RJB is grateful for funding from NSF (award 1205608) and the Partnership for Reduced Dimensional Materials for partial funding of this research, to Howard University Nanoscience Facility for access to liquid nitrogen, and the NSF-MRI program (grant No. CHE0619278) for funds to purchase the X-ray diffractometer. DFT calculations reported in this study were performed at TUBITAKULAKBIM, High Performance and Grid Computing Center (TRUBA resources). This study was supported by Hacettepe University Scientific Research Unit (Project no: THD-2020-18806).

Author contribution Zeki Büyükmumcu: Conceptualization, Data curation, Investigation, Formal analysis, Methodology, Resources, Review \& Editing, Validation, Visualization, Writing-original draft.

Sema Öztürk Yıldırım: Conceptualization, Data curation, Investigation, Formal analysis, Methodology, Resources, Review \& Editing, Supervision, Validation, Visualization, Writing-original draft.

Gökalp Çetin: Data curation, Investigation, Formal analysis, Validation, Visualization.

Rahime Şimşek: Conceptualization, Data curation, Investigation, Formal analysis, Funding, Methodology, Project Administration, Resources, Review \& Editing, Supervision, Validation, Visualization, Writingoriginal draft.

Ray J. Butcher: Data curation, Investigation, Formal analysis, Funding, Project Administration, Validation, Visualization.

Data availability The X-ray crystallographic data for the structures reported in this article have been deposited at the CCDC as supplementary data CCDC No. 2120865. These data can be obtained free of 
charge via http://www.ccdc.cam.ac.uk/ structure-summary-form the Cambridge Crystallographic Data Centre, 12 Union Road, Cambridge CB2 1EZ, UK; E-mail : deposit@ccdc.cam.ac.uk.

Code availability Not applicable.

Ethics approval Not applicable.

Conflict of interest The authors declare no competing interest

\section{References}

[1] Bandyopadhyay D, Salazar T, Gonzalez A (2017) Dihydropyridines as Calcium Channel Blockers: An Overview. Journal of Analytical \& Pharmaceutical

Research. https://doi.org/10.15406/japlr.2017.05.00148

[2] Safak C, Simsek R (2006b) Fused 1,4-Dihydropyridines as Potential Calcium Modulatory Compounds. Mini-Reviews in Medicinal Chemistry. https://doi.org/10.2174/138955706777698606

[3] Chen L, Deng H, Cui H, Fang J, Zuo Z, Deng J, Li Y, Wang X, Zhao L (2017). Inflammatory responses and inflammation-associated diseases in organs.

Oncotarget. https://doi.org/10.18632/oncotarget.23208

[4] Aggarwal BB, Shishodia S, Sandu SK, Pandey MK, Sethi G (2006) Inflammation and cancer: How hot is the link? Biochemical Pharmacology. https://doi.org/10.1016/j.bcp.2006.06.029

[5] Berkels R, Egink G, Marsen TA, Bartels H, Roesen R, Klaus W (2001) Nifedipine Increases Endothelial Nitric Oxide Bioavailability by Antioxidative Mechanisms.

Hypertension. https://doi.org/10.1161/01.hyp.37.2.240

[6] Cattaruzza M, Wachter R, Wagner AH, Hecker M (2000) Modulation by dihydropyridine-type calcium channel antagonists of cytokine-inducible gene expression in vascular smooth muscle cells. British Journal of Pharmacology. https://doi.org/10.1038/sj.bjp.0703192

[7] Costa S, Zimetti F, Pedrelli M, Cremonesi G, Bernini F (2010) Manidipine reduces pro-inflammatory cytokines secretion in human endothelial cells and macrophages. Pharmacological Research. https://doi.org/10.1016/j.phrs.2010.03.004

[8] Li X-Q, Cao W, Li T, Zeng A-G, Hao L-L, Zhang X-N, Mei Q-B (2009) Amlodipine inhibits TNF-a production and attenuates cardiac dysfunction induced by lipopolysaccharide involving PI3K/Akt pathway. International Immunopharmacology. https://doi.org/10.1016/j.intimp.2009.04.010

[9] Mason RP (2002) Mechanisms of plaque stabilization for the dihydropyridine calcium channel blocker amlodipine: review of the evidence. Atherosclerosis. https://doi.org/10.1016/s0021-9150(01)00729-8 
[10] Matsubara M Hasegawa K (2005) Benidipine, a dihydropyridine-calcium channel blocker, prevents lysophosphatidylcholine-induced injury and reactive oxygen species production in human aortic endothelial cells. Atherosclerosis. https://doi.org/10.1016/j.atherosclerosis.2004.08.020

[11] Preston Mason R (2003) Atheroprotective Effects of Long-Acting Dihydropyridine-Type Calcium Channel Blockers: Evidence from Clinical Trials and Basic Scientific Research. Cerebrovascular Diseases. https://doi.org/10.1159/000070272

[12] Öztürk Yıldııım S, Büyükmumcu Z, Butcher RJ, Çetin G, Şimşek R (2020) Synthesis and spectroscopic characterization and DFT study of benzyl 4-([1,1'-biphenyl]-4-yl)-2,6,6-trimethyl-5-oxo1,4,5,6,7,8-hexahydroquinoline-3-carboxylate. Journal of Molecular Structure. https://doi.org/10.1016/j.molstruc.2019.127069

[13] Sheldrick GM (2015) SHELXT - Integrated space-group and crystal-structure determination, Acta Cryst. https://doi.org/10.1107/S2053273314026370

[14] Farrugia LJ (2012) J. Appl. Crystallogr. https://doi.org/10.1107/ S0021889812029111

[15] Bruker (2002) SAINT. Bruker AXS Inc., Madison, Wisconsin, USA

[16] Bruker (2005) APEX2. Bruker AXS Inc., Madison, Wisconsin, USA

[17] Rigaku OD (2015) CrysAlis PRO. Rigaku Oxford Diffraction, Yarnton, England

[18] Clark RC, Reid, J.S. (1995). Acta Cryst. https://doi.org/10.1107/S0108767395007367

[19] a) Becke AD (1993) Density-functional thermochemistry. III. The role of exact exchange. J Chem Phys. https://doi.org/10.1063/1.464913

b) Lee C, Yang W, Parr RG (1988) Development of the Colle-Salvetti correlation-energy formula into a functional of the electron density. Phys Rev B. https://doi.org/10.1103/PhysRevB.37.785

[20] Frisch MJ et al. (2010) Gaussian 09, Revision B.01, Gaussian, Inc., Wallingford

[21] a) Lu T, Chen F (2012) Multiwfn: a multifunctional wavefunction analyzer. J Comput Chem. https://doi.org/10.1002/jcc.22885

b) Multiwfn- A Multifunctional Wavefunction Analyzer - (2021) Software Manual, Version 3.8 dev.

[22] Allen FH (2002) The Cambridge Structural Database: a quarter of a million crystal structures and rising, Acta Crystallographica. https://doi.org/10.1107/S0108768102003890

[23] El-Khouly A, Öztürk Yildirim S, Butcher RJ, Şimsek R, Şafak C (2012) 9-(5-Bromo-1 H-indol-3yl)-1,2,3,4,5,6,-7,8,9,10-decahydroacridine-1,8-dione dimethyl sulfoxide monosolvate, Acta Cryst. https://doi.org/10.1107/S1600536812045886 
[24] Öztürk Yildirim S, Butcher RJ, El-Khouly A, Şafak C, Şimsek R (2012) 3,3,6,6-Tetramethyl-9-(1-methyl1Hindol-2-yl)-1,2,3,4,5,6,7,8,9,10-decahydroacridine-1,8-dione, Acta

Cryst. https://doi.org/10.1107/S1600536812045722

[25] Gündüz MG, Butcher RJ, Öztürk Yildirim S, El-Khouly A, Şafak C, Şimşek R (2012) Ethyl 4-(5-bromo$1 \mathrm{H}$-indol-3-yl)-2,6,6-trimethyl-5-oxo-1,4,5,6,7,8-hexahydroquinoline-3-carboxylate, Acta

Cryst. https://doi.org/10.1107/S1600536812046909

[26] Cremer D \& Pople JA (1975) General definition of ring puckering coordinates, J. Am. Chem. Soc. https://doi.org/10.1021/ja00839a011

[27] Bernstein J, Davis R, Shimoni L, Chang N-L (1995) Angew. Chem. Int. Ed. Engl. 34:1555-1573

[28] Aihara J (2000) Correlation found between the HOMO-LUMO energy separation and the chemical reactivity at the most reactive site for isolated-pentagon isomers of fullerenes. Phys Chem Chem Phys. https://doi.org/10.1039/B002601H

[29] Glendening ED, Reed AE, Carpenter JE, Weinhold F (2001) NBO Version 3.1

[30] Bader R (1994) Atoms in Molecules: A Quantum Theory. Oxford University Press

[31] Zhao L, Pan S, Holzmann N, Schwerdtfeger P, Frenking G (2019) Chemical Bonding and Bonding Models of Main-Group Compounds. Chem Rev. https://doi.org/10.1021/acs.chemrev.8b00722

[32] Matta CF, Boyd RJ (2007) An Introduction to the Quantum Theory of Atoms in Molecules. In: Matta CF, Boyd RJ (ed) The Quantum Theory of Atoms in Molecules: From Solid State to DNA and Drug Design, Wiley-VCH Verlag GmbH \& Co. KgaA

[33] Emamian S, Lu T, Kruse H \& Emamian H (2019) Exploring Nature and Predicting Strength of Hydrogen Bonds: A Correlation Analysis Between Atoms-in-Molecules Descriptors, Binding Energies, and Energy Components of Symmetry-Adapted Perturbation Theory. J Comput Chem. https://doi.org/10.1002/jcc.26068

[34] Howard ST, Lamarche 0 (2003) Description of covalent bond orders using the charge density topology. J Phys Org Chem. https://doi.org/10.1002/poc.584

[35] Cooper S, Kaltsoyannis N (2021) Covalency in AnCl3 (An = Th-No). Dalton Trans. https://doi.org/10.1039/D0DT03699D

[36] Ziółkowski M, Grabowski SJ, Leszczynski J (2006) Cooperativity in Hydrogen-Bonded Interactions: Ab Initio and "Atoms in Molecules" Analyses. J Phys Chem A. https://doi.org/10.1021/jp060537k

[37] Espinosa E, Alkorta I, Elguero J, Molins E (2002) From weak to strong interactions: A comprehensive analysis of the topological and energetic properties of the electron density distribution involving $\mathrm{X}-\mathrm{H} \cdots$ 
F-Y systems. J Chem Phys. https://doi.org/10.1063/1.1501133.

[38] Becke AD, Edgecombe KE (1990) A simple measure of electron localization in atomic and molecular systems. J Chem Phys. https://doi.org/10.1063/1.458517

[39] Cioslowski J, Mixon ST (1991) Covalent bond orders in the topological theory of atoms in molecules, J. Am. Chem. Soc. https://doi.org/10.1021/ja00011a014

[40] Mayer I (1983) Charge, bond order and valence in the AB initio SCF theory. Chem Phys Lett. https://doi.org/10.1016/0009-2614(83)80005-0

[41] Mayer I, Salvador P (2004) Overlap populations, bond orders and valences for 'fuzzy' atoms. Chem Phys Lett. https://doi.org/10.1016/j.cplett.2003.11.048

[42] Lu T, Chen F (2013) Bond Order Analysis Based on the Laplacian of Electron Density in Fuzzy Overlap Space. J Phys Chem A. https://doi.org/10.1021/jp4010345

[43] Klein J, Khartabil H, Boisson JC, Contreras-García J, Piquemal JP, Hénon E (2020) New Way for Probing Bond Strength. J Phys Chem A. https://doi.org/10.1021/acs.jpca.9b09845

[44] The Document Foundation (2021) LibreOffice 7.1 Calc., https://www.libreoffice.org/discover/calc/ [45] Howard ST, Krygowski TM (1997) Benzenoid hydrocarbon aromaticity in terms of charge density descriptors. Can J Chem. https://doi.org/10.1139/v97-141

[46] Lu T (2021) Simple, reliable, and universal metrics of molecular planarity. J Mol Model 27. https://doi.org/10.1007/s00894-021-04884-0

[47] Wood BM, Forse AC \& Persson KA (2020). Aromaticity as a guide to planarity in conjugated molecules and polymers. J Phys Chem C. https://doi.org/10.1021/acs.jpcc.0c01064

[48] Zhang J (2018) LIBRETA: Computerized Optimization and Code Synthesis for Electron Repulsion Integral Evaluation. J Chem Theory Comput. https://doi.org/10.1021/acs.jctc.7b00788

[49] Lu T, Chen F (2012) Quantitative analysis of molecular surface based on improved Marching Tetrahedra algorithm. J Mol Graph Model 38. https://doi.org/10.1016/j.jmgm.2012.07.004

[50] Murray JS, Brinck T, Lane P, Paulsen K, Politzer P (1994) Statistically-based interaction indices derived from molecular surface electrostatic potentials: a general interaction properties function (GIPF). J. Mol. Struc.: THEOCHEM. https://doi.org/10.1016/0166-1280(94)80117-7

[51] Rice BM, Hare J, Byrd EFC (2007) Accurate Predictions of Crystal Densities Using Quantum Mechanical Molecular Volumes. J Phys Chem A. https://doi.org/10.1021/jp073117j

[52] Politzer P, Martinez J, Murray JS, Concha MC, Toro-Labbé A (2009) An electrostatic interaction correction for improved crystal density prediction. Mol Phy. 
[53] Liu Z, Lu T, Chen Q (2021) Intermolecular interaction characteristics of the all-carboatomic ring, cyclo[18]carbon: Focusing on molecular adsorption and stacking. Carbon 171. https://doi.org/10.1016/j.carbon.2020.09.048

\section{Figures}

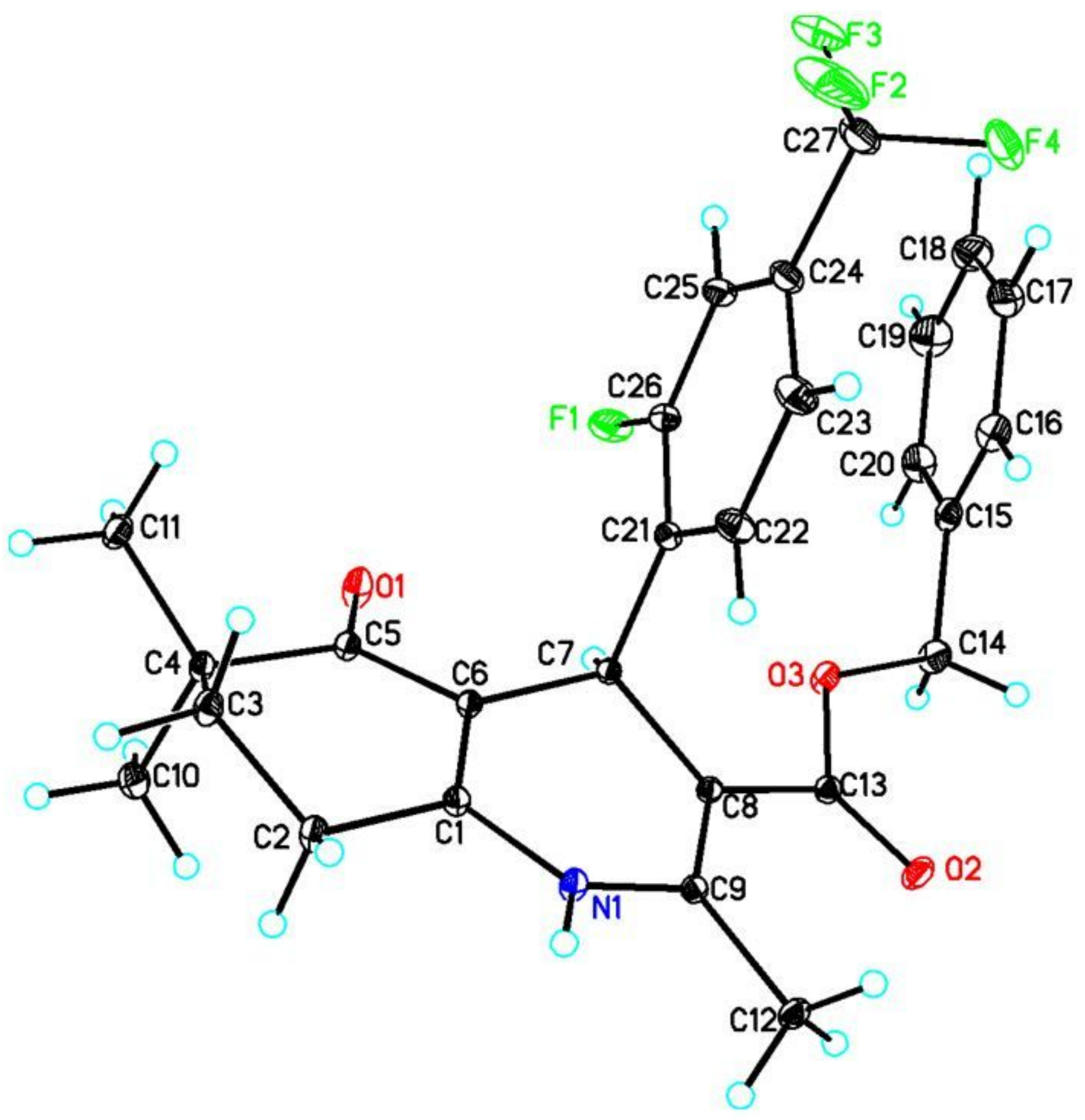


Figure 1

Drawing of the $\mathrm{C} 27 \mathrm{H} 25 \mathrm{~F} 4 \mathrm{NO} 3$ molecule obtained with the Ortep III program. Displacement ellipsoids are drawn at the $50 \%$ probability level.

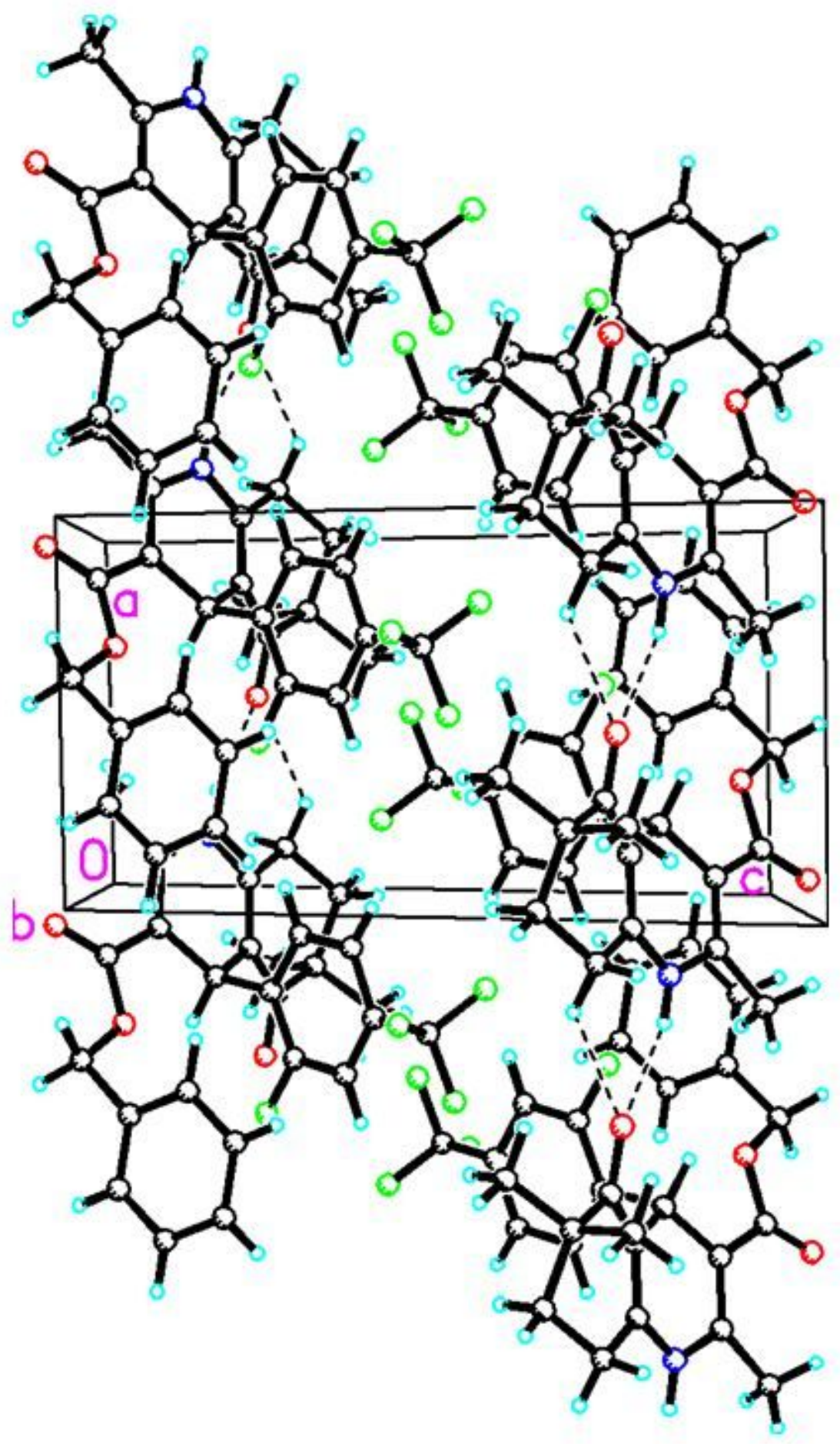

Figure 2 
The crystal packing of the title compound viewed along the $b$ axis. Hydrogen bonds are shown as dashed lines- see Table 3 for details.

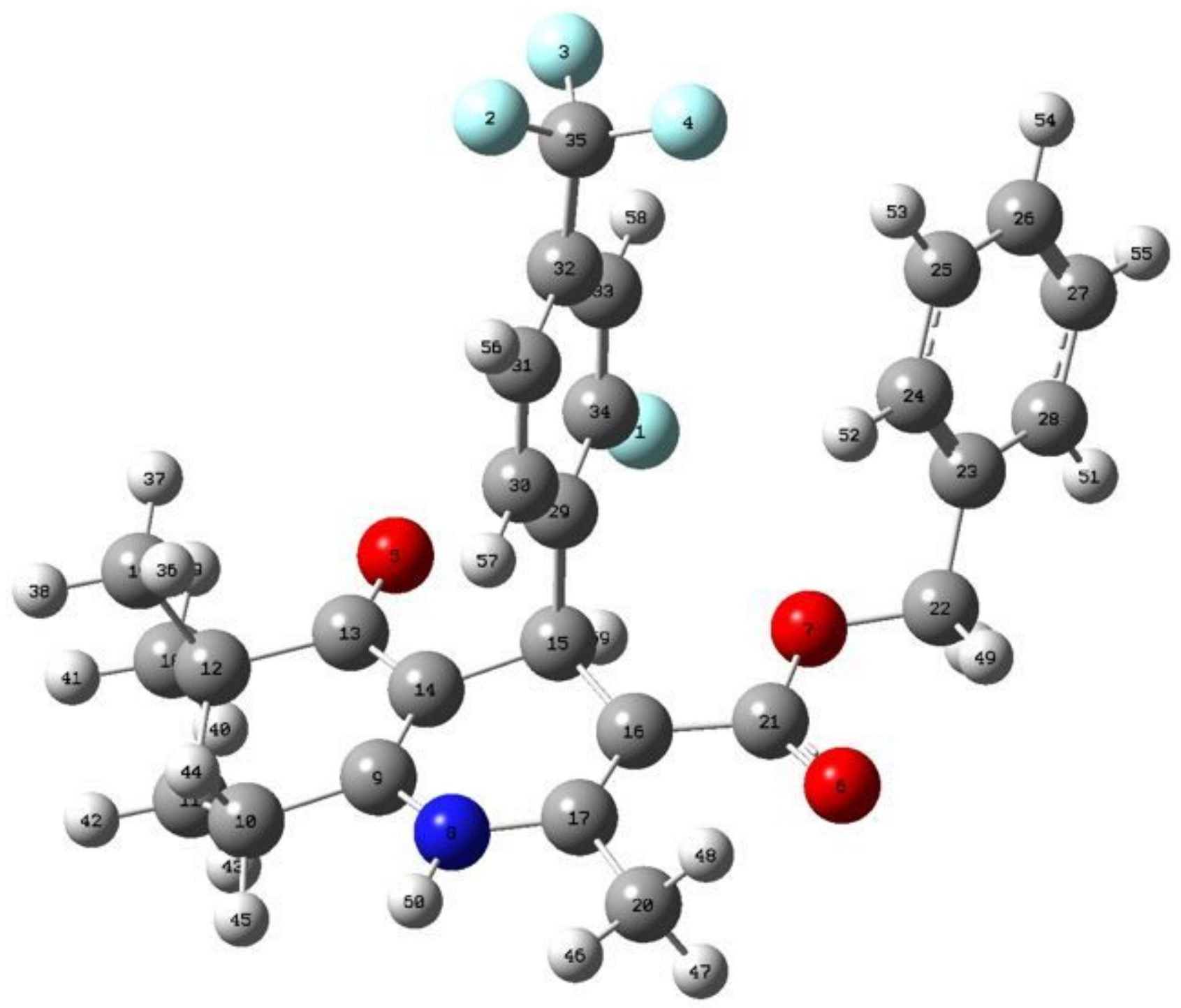

Figure 3

Optimized structure of title molecule by B3LYP. 


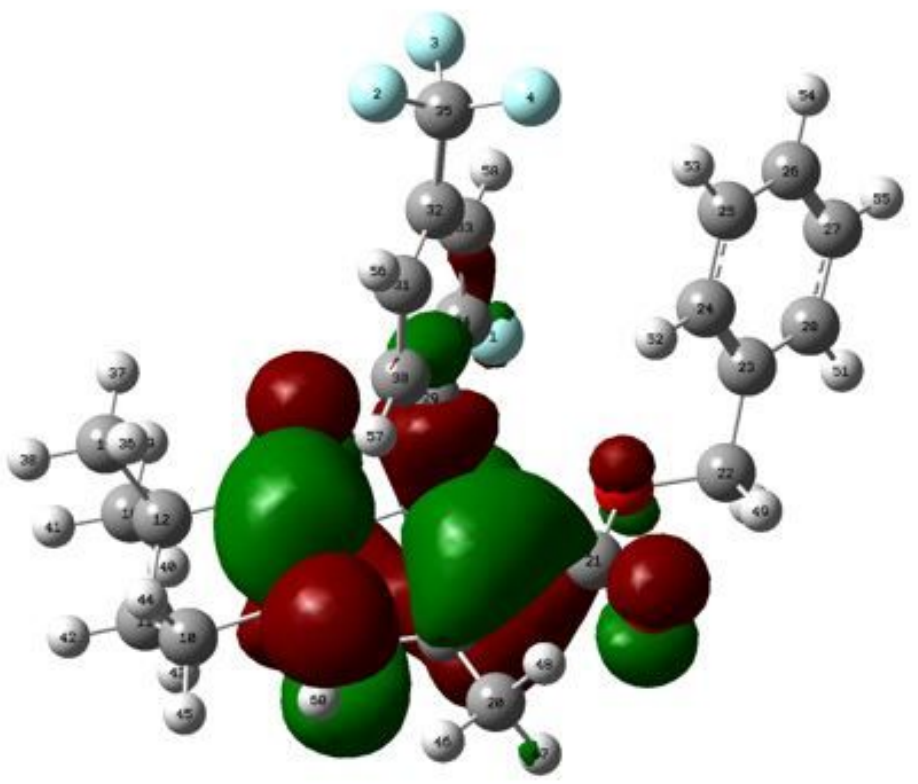

HOMO

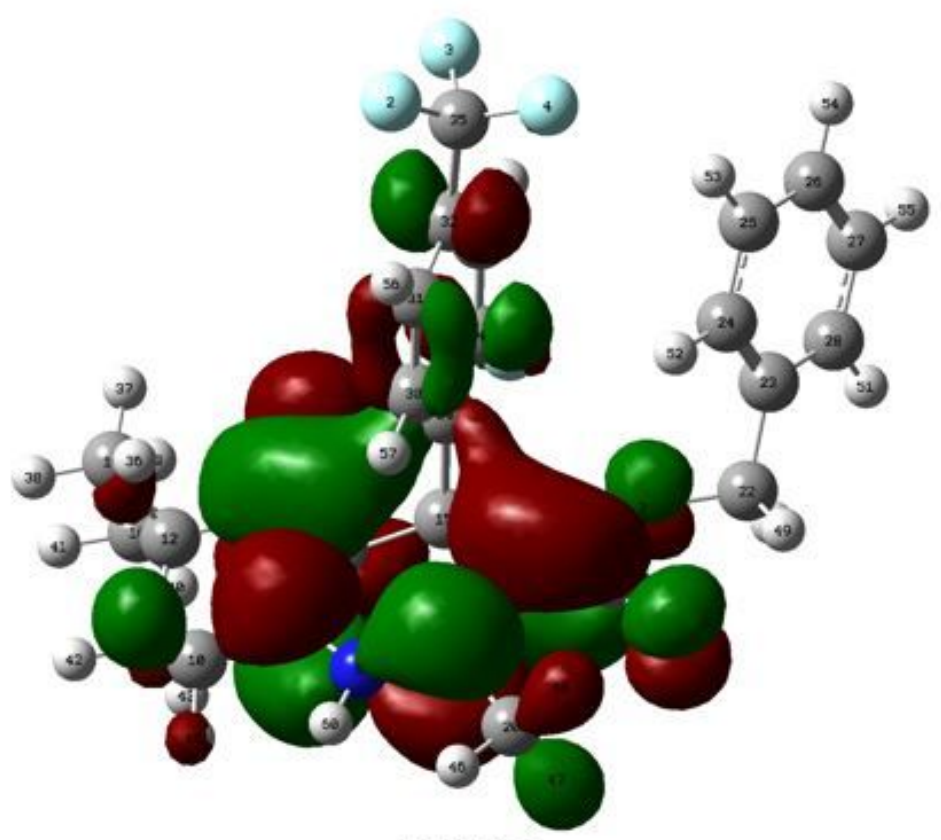

LUMO

Figure 4

The plots of the frontier orbitals of the title molecule.

\section{Supplementary Files}

This is a list of supplementary files associated with this preprint. Click to download.

- HURG111Scheme.docx

- HURG111SupplementaryInformationSI.sup

- STUCS2100645checkcifreport.pdf

- STUCS2100645.cif

- STUCS2100645.hkl 